\title{
Gaseous VOCs rapidly modify particulate matter and its biological effects - Part 1: Simple VOCs and model PM
}

\author{
S. Ebersviller ${ }^{1}$, K. Lichtveld ${ }^{1}$, K. G. Sexton ${ }^{1}$, J. Zavala ${ }^{1}$, Y.-H. Lin ${ }^{1}$, I. Jaspers ${ }^{1,2}$, and H. E. Jeffries ${ }^{1}$ \\ ${ }^{1}$ Environmental Sciences and Engineering, Gillings School of Global Public Health, \\ The University of North Carolina at Chapel Hill, USA \\ ${ }^{2}$ Center for Environmental Medicine and Lung Biology, Human Studies Facility, \\ The University of North Carolina at Chapel Hill, USA
}

Correspondence to: S. Ebersviller (sebersviller@gmail.com)

Received: 3 January 2012 - Published in Atmos. Chem. Phys. Discuss.: 14 February 2012

Revised: 11 December 2012 - Accepted: 17 December 2012 - Published: 21 December 2012

\begin{abstract}
This is the first of a three-part study designed to demonstrate dynamic entanglements among gaseous organic compounds (VOC), particulate matter (PM), and their subsequent potential biological effects. We study these entanglements in increasingly complex VOC and PM mixtures in urban-like conditions in a large outdoor chamber. To the traditional chemical and physical characterizations of gas and PM, we added new measurements of biological effects, using cultured human lung cells as model indicators. These biological effects are assessed here as increases in cellular damage or expressed irritation (i.e., cellular toxic effects) from cells exposed to chamber air relative to cells exposed to clean air. The exposure systems permit virtually gas-only- or PM-onlyexposures from the same air stream containing both gases and PM in equilibria, i.e., there are no extractive operations prior to cell exposure.

Our simple experiments in this part of the study were designed to eliminate many competing atmospheric processes to reduce ambiguity in our results. Simple volatile and semivolatile organic gases that have inherent cellular toxic properties were tested individually for biological effect in the dark (at constant humidity). Airborne mixtures were then created with each compound to which we added PM that has no inherent cellular toxic properties for another cellular exposure. Acrolein and p-tolualdehyde were used as model VOCs and mineral oil aerosol (MOA) was selected as a surrogate for organic-containing PM. MOA is appropriately complex in composition to represent ambient PM, and exhibits no inherent cellular toxic effects and thus did not contribute any biological detrimental effects on its own.
\end{abstract}

Chemical measurements, combined with the responses of our biological exposures, clearly demonstrate that gas-phase pollutants can modify the composition of PM (and its resulting detrimental effects on lung cells). We observed that, even if the gas-phase pollutants are not considered likely to partition to the condensed phase, the VOC-modified-PM showed significantly more damage and inflammation to lung cells than did the original PM. Because gases and PM are transported and deposited differently within the atmosphere and the lungs, these results have significant consequences for a wide range of people. For example, current US policies for research and regulation of PM do not recognize this "effect modification" phenomena (NAS, 2004).

These results present an unambiguous demonstration that - even in these simple mixtures - physical and thermal interactions alone can cause a modification of the distribution of species among the phases of airborne pollution mixtures that can result in a non-toxic phase becoming toxic due to atmospheric thermal processes only. Subsequent work (described in companion papers) extends the simple results reported here to systems with photochemical transformations of complex urban mixtures and to systems with diesel exhaust produced by different fuels.

\section{Introduction}

In its most-recent document summarizing the state of the science related to PM, the US National Research Council (NRC) stated that "a finding that the effect of particles 
depends on the concentration of another pollutant - that is, "effect modification" - would have implications for setting NAAQS [National Ambient Air Quality Standards] independently for the various criteria pollutants" (NAS, 2004).

This study was designed to demonstrate the existence of "effect modification" in a highly simplified system, and to increase the recognition of the atmosphere itself as a significant source of detrimental biological effects that are typically associated with PM. Researchers have long known that gases and particles interact in important and dynamic processes during the ageing of particulate matter $(\mathrm{PM})$ in the atmosphere. Volatile organic compounds (VOCs) are constantly shifting between the gas and particle phases of ambient air and at the same time can be modified by chemical reactions in each phase. Partitioning theory has evolved over decades, and has more recently been coupled to atmospheric chemistry models in an attempt to capture and characterize these interactions in a quantitative way (Kamens et al., 1981; Pankow et al., 1997; Kamens and Jaoui, 2001; Lee et al., 2004; Donahue et al., 2006; Hu and Kamens, 2007). What has remained uncharacterised to this point is if - and how - these interactions affect the actual toxicity of each phase. While toxicological co-pollutant effects such as synergism, antagonism, and the effects of pre-exposures have been investigated, much less is known about the direct effects of gas/particle interactions on the resulting toxicological risks resulting from changes in composition and dosimetry of both phases. Inclusion of these processes is necessary if the contribution of the atmosphere as a source of toxicity is to be modelled accurately in a laboratory setting.

Currently, most studies of the health implications of PM exposures focus primarily on the toxicity of extracted PM itself or on direct primary PM (e.g., Steenhof et al., 2011; Farina et al., 2011). This approach, while attractive to laboratory researchers, ignores the complexity of the air surrounding PM in the ambient environment, thereby missing the contribution of the atmosphere itself as a source of toxicity. The NRC states that "such approaches are likely to over-simplify the underlying biological processes and how the mixture of air pollutants that is inhaled adversely affects health" (NAS, 2004).

The absorbed dose of a VOC from the air is determined by both its lipophilicity and its ability to diffuse through water (McClellan and Henderson, 1995; Schwarzenbach et al., 2003; Salem and Katz, 2006). If airway cells are to absorb VOCs, the VOC must be transported to the air-liquid interface in the lung, where diffusion processes limit transfer of the VOC to the liquid layer. Compounds with high aqueous solubility will usually be taken out of the airway early. Conversely, compounds with low aqueous solubility may have very low absorption by the airway, and the bulk of the inhaled gas will be exhaled immediately. Dissolution into PM will not only deliver both of these classes of compounds to a region of the lung they would not normally enter, it will also hold them at an elevated concentration for an extended period of time, thereby increasing their overall dose to that region of the lung (and possibly to the body as a whole).

PM is able to bypass the diffusion-limited transfer of species across the aqueous layer above the surface of the cells in the airway. Bypassing this transfer brings partitioned VOCs into direct contact with the cellular membrane, thereby altering the dosimetry of the VOCs. When species are delivered to the cell surface in this manner, simple diffusion will push the VOCs from the particle into the cellular membrane, where they can reside until they are able to diffuse into the cell body (Becker et al., 2003; Schwarzenbach et al., 2003). Once apolar and low-polarity organics become infused in the lipid layer of the cell membrane, they can resist cellular clearance processes. When VOCs enter the cell in this manner, they will most likely be free of endosomal membranes - giving them free access to all compartments of the cell, including the nucleus (McClellan and Henderson, 1995; Becker et al., 2003). If the VOCs are metabolised by cellular processes or diffuse across the capillary membrane into the bloodstream, it will simply shift the partitioning equilibrium to cause more of the toxicant to diffuse into the cell's interior, thereby maintaining an elevated dose (Foster and Costa, 2005).

The purpose of this work is to demonstrate that physi$\mathrm{cal} /$ thermal processes among gases and particles can alter the delivery of air toxics to lung cells. This and subsequent studies (Ebersviller et al., 2012a,b) describe an integrated, stepwise approach to move from very simple systems to systems that approach the complexity of the ambient atmosphere. Altogether, these studies reveal the existence of inherent and acquired gas and particulate cellular toxic effects, and their dynamic entanglement, that is, they provide both chemical and biological effects data that demonstrate and defend the existence of PM "effect modification" as called for by the NRC.

\section{Methods}

\subsection{Experimental design}

Our total experimental design is divided into "simple" systems (in which no photochemistry occurs) and "complex" systems (in which species were photochemically oxidized in situ). The latter also include chamber injections of real emissions from a diesel engine operating with different fuels.

The results presented in Part 1 are based on the simplest system in which particle uptake of VOCs can be investigated. This simplicity is by design, and the main motivation behind creating such a highly simplified system is the desire to assign causality unambiguously. Thus, many competing processes have been removed to allow observations of the biological effects responses to PM exposure to be assigned to a very limited number of chemical and physical processes. 
To reduce the number of factors that had to be investigated to explain observed modifications to PM effects properties, a model PM material was selected. To be suitable for this study, the material had to produce a particle of sufficient complexity to be representative of atmospheric PM, but lack any inherent biological effects of its own. This approach is not an attempt to simulate the actual atmosphere, but to create a model suitable to illustrate contributions to the acquired biological effects properties of both the gas and particle phases.

Our experiments are only performed when the minimum outdoor temperature is forecast to be at least $15.0^{\circ} \mathrm{C}$. In the work presented here, the measured temperature range that occurred across all experiments was $16.5-28.0^{\circ} \mathrm{C}$. For experiments in which the chamber needed to be humidified, the chamber was first flushed with the output of a clean air generator to purge background VOCs below the limit of detection of our Varian 3800 gas chromatographs (ca. 1-3 ppbV), and then humidified with HPLC-grade water to a dew point (DP) of at least $16.0^{\circ} \mathrm{C}$, but less than $19.0^{\circ} \mathrm{C}$. While this narrow range of DP may not represent the entire range of relative humidities that may be encountered in the ambient environment, it does limit variability in the system caused by humidity effects while still avoiding false-positives from biological effects endpoints caused by desiccation of the cells. To remove the possibility that either the VOCs or the PM used in these experiments might be modified by photochemical processes, all experiments were performed in the large outdoor chamber at night.

In vitro cell cultures were exposed to six types of air mixtures: clean air, clean air containing mineral oil aerosol (MOA), clean air containing a single volatile organic compound (VOC) only (with no aerosol present), and clean air with a single VOC but with MOA added. To explore the degree to which volatility alters the uptake of VOCs by PM, single VOCs in both the volatile and semi-volatile range were selected (bringing the total number of air mixtures to six). No cells were exposed to both VOCs at one time. The goal of this work is not to compare the toxicity of specific VOCs and, as such, the biological responses of the lung cells will not be cross-compared between VOCs.

\subsection{Chamber}

UNC's atmospheric chemistry groups use environmental irradiation chambers (smog chambers) to study the dynamics of the chemical and physical processes that occur naturally in the atmosphere (Jeffries et al., 1976, 1985; Kamens et al., 1981; Sexton et al., 2004; Doyle et al., 2007). The chambers allow complex atmospheres to be generated repeatedly in a controlled environment, but still aged in a more-realistic manner than has previously been available to toxicologists. More recently, the chambers have been coupled directly to two in vitro exposure systems capable of evaluating the relative toxicities of both the gas and particle phases of air pollution mixtures while maintaining the equilibria between the gas and particle phases throughout exposure (Doyle et al., 2004, 2007; Sexton et al., 2004; de Bruijne et al., 2009b). Due to the dynamic nature of the atmospheric processes involved, the retention of these equilibria is vital to an accurate estimate of the effects of exposure to airborne pollutants. These characteristics, when combined, lend themselves to a very simple approach for investigating the direct modification of particle toxicity by the gas phase. The UNC smog chambers are, therefore, uniquely suited to explore the processes of interest here.

The studies described here used the Gillings Innovation Laboratory $120 \mathrm{~m}^{3}$ chamber on the roof of the Gillings School of Global Public Health at UNC and the sampling and biological analysis laboratories located directly below it (Fig. 1). The chamber is equipped with a high-volume vent fan connected to a HEPA filter that removes PM from ambient air during large-volume flushing of the chamber. In addition, the chamber is connected to a commercial clean air generator (Addco Generator Model 737, $250 \mathrm{~L} \mathrm{~min}^{-1}$ ) that scrubs moisture, VOCs and PM from air before it enters the chamber. Pollutants to be studied (VOCs, PM, etc.) can be injected into the chamber through its floor. Mixing fans in the interior of the chamber ensure uniform distribution of species to be tested. In all experiments described in this manuscript, mixing fans were turned off five minutes after the completion of chamber injections to minimize loss of PM to the chamber walls. Although the mixing fans were not in operation throughout the duration of the experiments, chamber contents were still mixed by thermal and wind-driven motion of the large walls. Chamber contents are monitored continuously via sample lines that pass through the floor of the chamber, the roof of the building, and into the laboratory below (ca. $6 \mathrm{~m}$ in length). The sample lines are made of a variety of materials to accommodate both the analytical and toxicological needs of the laboratory. The laboratory is equipped with a suite of analytical instruments that sample the chamber directly, allowing detailed analysis of its contents to be performed in real-time. For analytes that may be lost in long transfer lines, samples are collected directly below the chamber on the roof of the building (via ca. $1 \mathrm{~m}$ of sample line).

\subsection{Choice of gases and particles to test}

Several volatile organic compounds (VOCs) were considered for inclusion in this study of gas/particle interactions. The VOC species chosen have been detected in our own chamber experiments involving complex VOC systems, and were also reported by Grosjean et al. in a study of carbonyl compounds measured at the inlet and outlet of a highway tunnel (Grosjean et al., 2001). Candidate species that were reported in multiple studies, or known to be of particular interest to air pollution researchers, were given preference in selection (Grosjean et al., 2001; EPA, 2012).

We selected p-tolualdehyde (TOLALD) to represent a semi-volatile species likely to be in both the gas and particle 


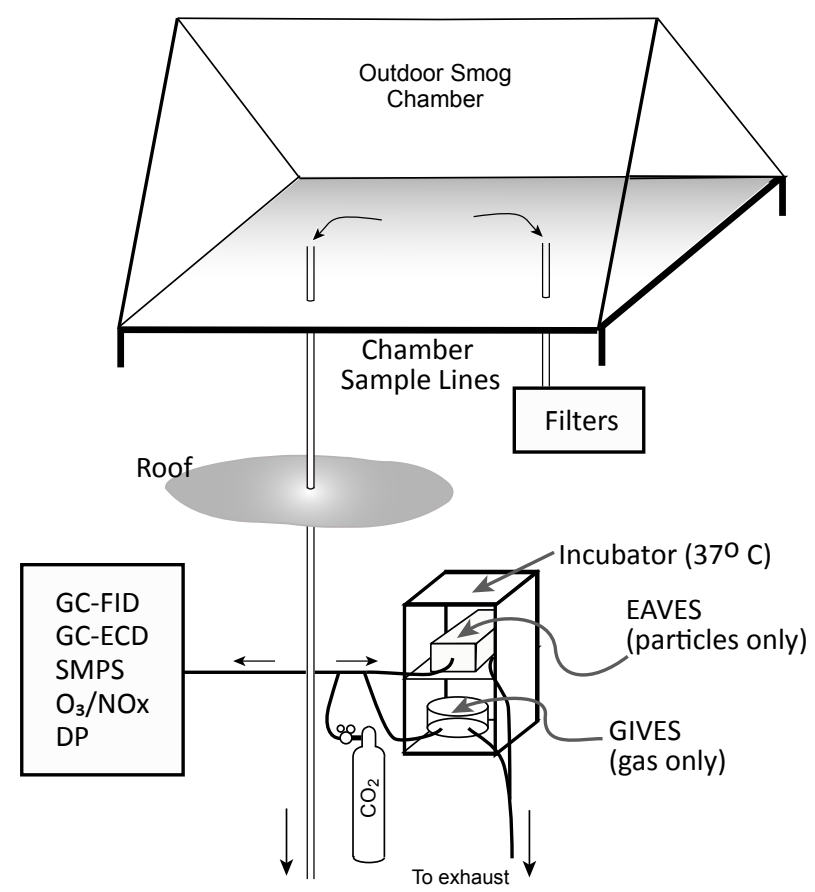

Fig. 1. Chamber schematic. Sample lines pass through the floor of the chamber, the roof, and then directly into the laboratory below. Filter sampling is performed on the roof of the building to minimize loss to the sample lines.

phases in the ambient environment (96\%; Sigma-Aldrich, St. Louis, MO). Along with its tendency to be present in both phases, it is a first generation oxidation product of vinylaromatic compounds and has an aldehyde function while retaining its aromatic function. It is a known respiratory irritant, producing a burning sensation, bronchial constriction, choking and coughing (Clayton et al., 1982). We selected acrolein (ACRO) to represent a more-volatile species generally considered unlikely to be in the particle phase (95\%; Sigma-Aldrich, St. Louis, MO). In addition to ACRO being on the EPA's "Dirty Thirty" list of toxicants, we have extensive experience using acrolein for both chemical and toxicological tests.

Mineral oil aerosol (MOA) was used as a surrogate for organic-containing ambient PM (pharmaceutical grade, $100 \%$ ). Exposure to mineral oil elicits no acute biological effects from lung cells, making mineral oil an ideal PM material for this study. While most ambient PM has a mixture of elemental and organic carbon (EC/OC), the $\mathrm{EC}$ fraction is at the core of the particle and is (generally) completely surrounded by an OC layer. What this means is that any interactions between the PM and the gas phase happens via the OC fraction. In addition, mineral oil aerosolised with a large Collison nebuliser (May, 1973) has a size distribution similar to diesel exhaust particles observed in other chamber studies. For this study, MOA is a convenient and sufficiently complex surrogate for ambient PM that contains organic material.
Prior to use, all mineral oil was steri-filtered in the laboratory to remove any particulate or biological contaminants. In addition, the very large negative pressure required to pull the mineral oil through the small pores of the filter apparatus served as a mechanism by which to remove any dissolved VOCs which may alter the toxicity of the aerosol. The steri-filtered mineral oil was kept sealed and stored in a sterile laboratory to minimize the possibility that the filtered stock would absorb gaseous VOCs from laboratory air in our chemistry/exposure laboratory. For experiments in which particles were needed, a large-volume Collison nebuliser was used to aerosolise mineral oil directly into the chamber, to a concentration of ca. $1.4 \mathrm{mg} \mathrm{m}^{-3}$, as determined by SMPS (described below).

\subsection{Gas phase compositional analysis}

The gas-phase composition and dilution rate of the chamber were monitored continuously by two Varian 3800 gas chromatographs (GCs), one with an electron capture detector (ECD) and the other with a flame ionization detector (FID). As stated above, the sample lines feeding the GCs travel from the floor of the chamber, through the roof of the building, and directly to the GCs in the laboratory below. The GC-FID has dual packed columns (one for light hydrocarbons, the other for heavy and aromatic hydrocarbons) and uses helium as a carrier gas. The GC-ECD has a single packed column, and is used for measurement of electron-accepting species. The GC-ECD uses a blend of argon and methane as a carrier gas. Each GC was equipped with an automated valve system that sampled the chamber contents every $30 \mathrm{~min}$, and was run at a static temperature throughout sampling.

A Varian 3800 GC with Saturn 2200 mass spectrometer (MS) was used to analyse off-line samples (such as functionspecific or filter samples). The GCMS is also equipped with an FID, uses an RTX-5 fused-silica capillary column $(60 \mathrm{~m}$ long, $0.32 \mathrm{~mm}$ ID, $0.5 \mu \mathrm{m}$ film thickness; Restek US, Bellefonte, PA) and was operated under a temperature-optimized elution program with helium as the carrier gas. Initially, the MS was operated in EI mode, and the ion trap was set to collect all mass fragments from 40-650 mass units. When increased sensitivity was desired, the ion trap was programmed to retain fragments with a more-focused range of sizes.

All of these instruments have conservative limits of detection of ca. 1-3 ppbV for VOCs.

\subsection{Particle phase analysis}

\subsubsection{Scanning mobility particle sizer}

During all experiments, the size distribution and mass concentration of the aerosols in the test atmospheres were monitored with a Scanning Mobility Particle Sizer (SMPS - TSI 3081 Differential Mobility Analyser (DMA) with TSI 3022A Condensation Particle Counter; TSI Inc., St. Paul, MN). The 
instrument quantified particles from 19 to $882 \mathrm{~nm}$ in diameter. The SMPS was set to scan continually on a 3 min-persample cycle ( $150 \mathrm{~s}$ up-scan, $30 \mathrm{~s}$ down-scan; $0.3 \mathrm{~L} \mathrm{~min}^{-1}$ sample flow rate, $3.0 \mathrm{~L} \mathrm{~min}^{-1}$ sheath air flow rate). The particle size distributions, as well as number and estimated mass concentrations were logged continually for each experiment. Estimated mass concentrations were calculated by multiplying the volume concentration distribution (from the SMPS) by the density of mineral oil $\left(0.843 \mathrm{~g} \mathrm{~mL}^{-1}\right.$, determined inhouse for steri-filtered mineral oil). This assumes that the density of the MOA was not modified significantly by the partitioned VOCs. To determine whether a super-micron PM mode was present (which would be unobservable with the SMPS), occasional measurements were made with a TSI Dusttrak (DRX Aerosol Monitor 8534; TSI Inc., St. Paul, MN).

\subsubsection{Filters}

Teflon membrane filters ( $2 \mu \mathrm{m}$ pore size, $47 \mathrm{~mm}$ diameter: Pall Corporation, New York) were used to collect particles at an average flow rate of $17.5 \mathrm{~L} \mathrm{~min}^{-1}$ for $1-4 \mathrm{~h}$. Filters were collected concurrently with exposure periods. Static was removed from the filters prior to weighing both before and after sampling. These procedures were carried out efficiently so that the filter was exposed to laboratory air as little as possible to minimize the loss of VOCs during weighing. After each filter was weighed, it was placed in a certified-clean sample jar, and spiked with Storage Internal Standard (IS) to characterize the loss of VOC with storage. Then each jar was sealed with Parafilm and placed immediately into a $-20^{\circ} \mathrm{C}$ freezer for storage until extraction and analysis. The aerosol mass concentration in the air was calculated by dividing the mass collected on the filter by the total volume of air sampled during collection. This value was used as a check against the value calculated from SMPS data. All mass concentration values reported in this manuscript, however, represent filterderived measurements.

\subsubsection{Species-specific analysis of carbonyls}

Filter samples were analysed by a modified protocol using o(2,3,4,5,6-pentafluorobenzyl) hydroxylamine chloride (PFBHA). PFBHA is used to selectively sample for carbonylcontaining organic compounds (Yu et al., 1995, 1997; Liu et al., 1999b,a; Healy et al., 2008). PFBHA selectively derivatises carbonyl-containing functional groups of organic species, with preference given to aldehydes and ketones over organic acids and esters. Mass spectra of PFBHA-derivatised carbonyl-containing compounds display a signature peak at $m / z=181$ that is usually the base peak of the spectrum. In this study, filter samples were incubated under a PFBHA solution (after sample collection) to collect carbonylcontaining species from the condensed phase. Sample processing and analysis were then carried out as described be- fore (Yu et al., 1995, 1997; Liu et al., 1999b,a; Healy et al., 2008). All filter samples from this study were analysed by GCMS (as stated above), using a large-volume injection liner to increase the sensitivity of the instrument (Termonia et al., 1988).

\subsection{Biological effects model and measurements of response}

Cultured human epithelial lung cells, type A549, were used as the biological receptor model in this study. A549 human respiratory cells are a commercially available cell line that has been shown to react in a manner that is representative of the human airway in vivo (Lieber et al., 1976; ATCC, 2011). While we concede that, in certain circumstances, primary lung cells may be a more desirable model than an immortalized cell line, A549 cells (which lack the individualto-individual susceptibility variations of the primary lines) are used worldwide, allowing for easier replication of experiments, and are perfectly suited for this demonstrationof-principle work.

The A549 cells were grown on membraneous supports in complete media (FBS: F12K medium, $10 \%$ fetal bovine serum, and $1 \%$ penicillin and streptomycin; Invitrogen, Carlsbad, CA) until confluency (until the cellular coverage was uniform across the entire membrane as determined by visual inspection of each membrane by confocal microscopy). Any membranes that were not confluent or had irregular cellular coverage were discarded (were not used for exposure). At least four hours prior to exposure, the FBS media was removed from the apical (top) and basolateral (bottom) compartments of the cell cultures and replaced with "starving" media (BSA: F12K medium, $1.5 \mu \mathrm{g} \mathrm{mL}^{-1}$ bovine serum albumin, and $1 \%$ penicillin and streptomycin; Invitrogen, Carlsbad, CA) to slow their rate of replication. Immediately prior to exposure, the basolateral BSA media was replaced with fresh aliquots of BSA, while the apical media was removed and not replaced. This established an air-liquid interface (ALI) at the cellular surface.

The Gas In Vitro Exposure System (GIVES) and Electrostatic Aerosol in Vitro Exposure System (EAVES), described in more detail below, allow the cellular toxicity of the gaseous and particle phase components of the same air pollution mixture to be evaluated virtually independently of one another, and with no substantive modification to the sample prior to exposure. This allows cells to be exposed to pollutants as they might be found in the ambient environment. These exposure systems, as models of the human deep lung, are intended to be biosensors - a means by which to further characterize the distribution of species among the gas and particle phases, and to indicate which systems warrant further evaluation for harmful biological effects. This is measured by gauging cellular responses to treatment air exposures relative to clean air exposures. 
Following exposure, all cell culture samples were allowed to express their responses for $9 \mathrm{~h}$ in clean air in an incubator. After the $9 \mathrm{~h}$ of expression, basolateral supernatants (media below the cells) were collected. All liquid samples were stored at $-20^{\circ} \mathrm{C}$ for later analysis of toxicological endpoints (see below).

\subsubsection{Gas in Vitro Exposure System (GIVES)}

Gas exposures from the chamber occur in air-tight, eight litre, cylindrical modular cell-exposure chambers (BillupsRothenberg, MIC-101TM, Del Mar, CA), as described before (Jaspers et al., 1997; Doyle et al., 2004; Sexton et al., 2004). Briefly, the modular chamber holds tissue culture plates containing Transwells (Costar 12-membrane plates, $0.4 \mu \mathrm{m}$ pore size, Cambridge, MA) for concurrent exposures. The inlet of the exposure chamber is connected to a sampling manifold coupled directly to the smog chamber on the roof (Doyle et al., 2004; Sexton et al., 2004; Doyle et al., 2007). The sample rate through the cell-exposure chamber is $1 \mathrm{~L} \mathrm{~min}{ }^{-1}$. Exposure of cell cultures in the GIVES lasted $4 \mathrm{~h}$.

Because there are no forces other than gravity and the $1 \mathrm{~L} \mathrm{~min}-1$ air circulating through the GIVES exposure chamber, it is very difficult for any PM to deposit on cells in this sampler. We have performed a series of calculations with a range of assumptions to estimate the time that might be needed in the GIVES to achieve the same PM exposure as in the EAVES sampler, which for test conditions herein was $1.5 \mu \mathrm{g}$ in one hour of sampling. Adopting a PM settling velocity of $2.86 \times 10^{-3} \mathrm{~cm} \mathrm{~s}^{-1}$ (Hinds, 1999) for the mass-mode-diameter particles in our chamber tests conditions $(1000 \mathrm{~nm}$; of which there were about 82 particles per $\mathrm{cm}^{3}$ ), and applying our various assumptions we have calculated that to collect an equivalent PM mass in the GIVES by settling alone would require ca. 150 days. At the other extreme, if every particle that entered the GIVES were deposited uniformly over the entire sampler floor surface (including the cell wells), we would still need 12 hours to achieve the same mass. Of course, there is no force in the GIVES that would result in all or even a significant fraction of PM being deposited.

Thus, cells in the GIVES do have some exposure to PM in the air stream, but the extent is so limited that it cannot be detected by biomarker changes, making this sampler virtually a gas-only sampler.

\subsubsection{Electrostatic Aerosol in Vitro Exposure System (EAVES)}

The Electrostatic Aerosol in Vitro Exposure System (EAVES) is a necessary and sufficient sampler to test the basic hypothesis in this study. The EAVES is designed to expose human lung cells directly to particles without prior collection in media, thereby providing an efficient and effective alternative to more conventional particle in vitro exposure methods (Lichtveld et al., 2012).

Briefly, this sampler operates in a tissue culture incubator maintained at $37^{\circ} \mathrm{C}$ with appropriate humidity and $5 \%$ carbon dioxide added to the flow to achieve conditions conducive to cell viability during the exposure time. Sample flow rate through the EAVES device is $1 \mathrm{~L} \mathrm{~min}^{-1}$. A $0.8 \mathrm{~cm}$ high, rectangular cross-sectional laminar flow of sample air (with gases and PM) first moves through a corona charging region where PM in the sample stream receives a slight electrical charge. The flow then proceeds through a $0.6 \mathrm{~cm}$ high rectangular cross-sectional channel between an anodizedaluminium grounded collection plate (below) and a charged repeller plate above (with polarity matched to the corona region). In the grounded collection plate, a $0.6 \mathrm{~cm}$ deep well that is $3.5 \mathrm{~cm}$ in diameter holds a titanium dish with BSA media and four tissue culture inserts. The charged particles are forced to move across the laminar flow and (in less than $0.4 \mathrm{~s}$ ) deposit on the collection plate. Because the deposition and flow parameters have been optimized, a large number of particles are gently deposited on the air-liquid interface of the cell culture inserts $\left(0.69 \mathrm{~cm}^{2}\right.$ each $)$ in the well. Complete design details and performance tests are given by de Bruijne et al. (2009b).

Prior testing of the direct exposure EAVES sampler reported by de Bruijne et al. (2008, 2009a,b) demonstrated that in an hour long exposure: (1) no significant cytotoxicity or inflammatory mediator production occured from cellular exposure to the electrical field; (2) no cellular response was observed due to the low ozone concentration produced by the corona charging system; (3) no cellular response was observed due to the electrical charges added to the PM; (4) no secondary organic aerosol formation was observed from very-reactive VOCs flowing through the sampler; (5) no cellular response was observed following exposure to toxic gases without PM present; and (6) no response was observed when mixtures of toxic gases and PM pass through the sampler without the deposition field on, while a significant response was observed from the same mixture when deposition field was applied.

While it is true that toxic gases do flow through the EAVES, the flow is highly laminar and the cells are contained in the well below the flow of sampled air. Repeated tests have demonstrated that, while there might be some gaseous exposure, its effects can not be detected in biomarker analysis following a 1-h long exposure. Therefore, the EAVES sampler can expose cells to PM while maintaining equilibria with the gaseous components of the atmosphere being sampled, and with no observable response caused by the operation of the device. Thus, the EAVES sampler is, under the conditions used here, virtually a PM-only exposure system.

Cells exposed in the EAVES device are grown on Millicell membranes (Costar, Cambridge, MA) as described before (de Bruijne et al., 2009b). The durations of exposure for membranes in the EAVES device were determined by the 
particle mass concentration in the air for each experiment, and lasted between $30 \mathrm{~min}$ and one hour. The exposure duration was varied to ensure equal deposition of PM on the cellular surface, while still providing ample time for a dose of PM to be delivered to the cells that was sufficient to elicit a response. For experiments in which no PM was present, the duration of exposure in the device (with the deposition field on) was matched to the corresponding experiment with PM (i.e., TOLALD only exposure time was matched to the duration of exposure for TOLALD with PM).

\subsubsection{Control exposures}

In addition to each pollutant mixture listed above, cells were exposed to clean chamber air with each exposure system, as well as to incubator air. The response of the clean air exposure was compared to incubator controls to ensure that they were equal (as determined by a t-test, $p=0.05$ ). The response of cells to clean air exposure was then used as a normalizing factor for the response of cells to each of the pollution mixtures.

\subsubsection{Biological effects endpoints (cytotoxicity and inflammation)}

Cytotoxicity is expressed as increase of lactate dehydrogenase (LDH) levels over clean air controls. LDH is only released by cells when the integrity of their cellular membranes have been compromised through either damage or failure (apoptosis). LDH levels were measured using a Cytotoxicity Detection Kit (TaKaRa Bio Inc., Tokyo, Japan). Interleukin 8 (IL-8) cytokine is an inter-cellular signalling protein that is released by cells in response to stimulus by an irritant. IL-8 release was evaluated using an ELISA kit (BD Biosciences, San Diego, CA). Though it has been noted previously that the presence of PM interferes with the proper functioning of ELISA kits (Seagrave et al., 2004), it was determined that this interference was not an issue with the PM used in this study. Inflammatory response is reported as increase of IL-8 levels over clean air controls.

Tables of response ratios accompany bar charts of endpoint measurements. Response ratios were calculated by dividing the cellular response to the exposure listed in the column heading of the table by the response to the exposure listed in the first column. For example, in Table 2, the gasonly response to TOLALD by itself (Exp. C) was 3.21 times higher than the clean air exposure (Exp. A). The gas-only response to TOLALD with MOA, however, was 0.83 (Exp. D). Therefore, in Table 2, the ratio of their responses is given by $(0.83 / 3.21)=0.26$ meaning that the response of cells exposed to TOLALD with MOA by the gas-only method was roughly one quarter the response observed from cells exposed to TOLALD alone (or, the response for TOLALD was 3.85 times greater than was observed for TOLALD with MOA). All results and further discussion are given below.

\subsection{Statistical analysis}

All calibration curves were tested by fitting a linear least squares line through the data. Calibration factors were calculated for each species to be analysed, with appropriate propagation of uncertainty. All instrument measurements are reported as the mean $\pm 95 \%$ confidence interval, unless otherwise stated.

For toxicity endpoints, replicate tests of the same sample were averaged, and cell samples exposed to the same air mixture (i.e., incubator control, clean air control, GIVES exposure, etc.) were grouped for one-way analysis of variance (ANOVA - GraphPad Prism Software, La Jolla, CA). ANOVA analysis was used to determine whether there were statistically-significant differences between the cellular responses to each exposure mixture and their corresponding controls. Cellular response to insult is expressed as the mean \pm standard error. The independent variable is exposure. Pair wise comparison (treatment vs. control) was performed as a subtest of the overall ANOVA. Group differences were considered significant if the test statistical type 1 error $p \leq 0.05$.

\section{Results}

\subsection{Gas phase compositional analysis}

The gas-phase conditions during exposure, as well as particle mass concentrations, are summarized in Table 1 . There were no VOCs detected in the chamber during either clean air exposure (with or without MOA). There was a slight variation in the concentration of TOLALD between exposures, though a difference of $178 \mathrm{ppbV}$ (ca. $9 \%$ ) should not be enough to cause a significant discrepancy in response from the cells. The ACRO exposures were more closely matched (a difference of $8 \mathrm{ppbV},<1 \%)$. Relative humidities $(\mathrm{RH})$ are presented for each exposure mixture in the chamber air (where it might impact partitioning dynamics) as well as in the incubator (where variations in RH might affect cellular response). The uncertainty reported in Table 1 represents the $95 \%$ confidence interval.

\subsection{Particle phase characterization}

The particle mass concentrations across all of the exposures in which no particles were added were close to the limit of detection for the SMPS instrument (as determined by the averages and $95 \%$ confidence intervals reported in Table 1). The particle mass concentrations for the exposures in which MOA was added to the chamber were ca. 1500 times higher than the exposures without PM (calculated from TSP filters), well above the level of uncertainty (Table 1). No change was observed in the mode particle diameter (by number) when VOCs and MOA were mixed in the chamber (relative to MOA in clean air; Fig. 2). The mass mode diameter is unclear from these data, as the peak is off-scale for the SMPS 
Table 1. Exposure Conditions. All measurements represent the mean value $\pm 95 \%$ confidence interval.

\begin{tabular}{|c|c|c|c|c|c|c|c|}
\hline \multicolumn{4}{|c|}{ Experimental Condition $^{\mathrm{a}}$} & \multirow{2}{*}{$\begin{array}{l}\begin{array}{l}\text { Avg. VOC Conc. } \\
(\mathrm{ppmV})\end{array} \\
\mathrm{ND}^{\mathrm{b}}\end{array}$} & \multirow{2}{*}{$\begin{array}{c}\begin{array}{c}\text { PM Conc. } \\
\left(\mathrm{mg} \mathrm{m}^{-3}\right)\end{array} \\
0.001 \pm 0.001\end{array}$} & \multirow{2}{*}{$\begin{array}{c}\begin{array}{c}\text { RH Chamber } \\
(\%)\end{array} \\
47.8 \pm 0.3\end{array}$} & \multirow{2}{*}{$\begin{array}{c}\begin{array}{c}\text { RH Exposure } \\
(\%)\end{array} \\
31.7 \pm 0.1\end{array}$} \\
\hline A. & Clean Air & & & & & & \\
\hline B. & Clean Air & & w/MOA & $\mathrm{ND}^{\mathrm{b}}$ & $1.561 \pm 0.027$ & $69.2 \pm 1.0$ & $30.1 \pm 0.4$ \\
\hline C. & Clean Air & TOLALD & & $2.012 \pm 0.102$ & $0.001 \pm 0.003$ & $73.8 \pm 2.3$ & $34.3 \pm 1.0$ \\
\hline D. & Clean Air & TOLALD & w/MOA & $1.834 \pm 0.057$ & $1.317 \pm 0.007$ & $68.6 \pm 2.2$ & $30.8 \pm 0.8$ \\
\hline E. & Clean Air & ACRO & & $0.937 \pm 0.053$ & $0.007 \pm 0.001$ & $70.9 \pm 0.8$ & $39.4 \pm 0.1$ \\
\hline F. & Clean Air & ACRO & w/MOA & $0.929 \pm 0.095$ & $1.415 \pm 0.027$ & $92.6 \pm 0.4$ & $32.3 \pm 0.3$ \\
\hline
\end{tabular}

a MOA is mineral oil aerosol, ACRO is acrolein, TOLALD is p-tolualdehyde, and RH is relative humidity.

${ }^{\mathrm{b}}$ None detected; detection limit approximately 0.001 to $0.003 \mathrm{ppmV}$.

$\mathrm{c}^{\mathrm{T}}$ The RH of the air in the outdoor chamber (ambient temp.).

${ }^{\mathrm{d}}$ The RH of the air in the in vitro exposure systems $\left(37.0^{\circ} \mathrm{C}\right)$.

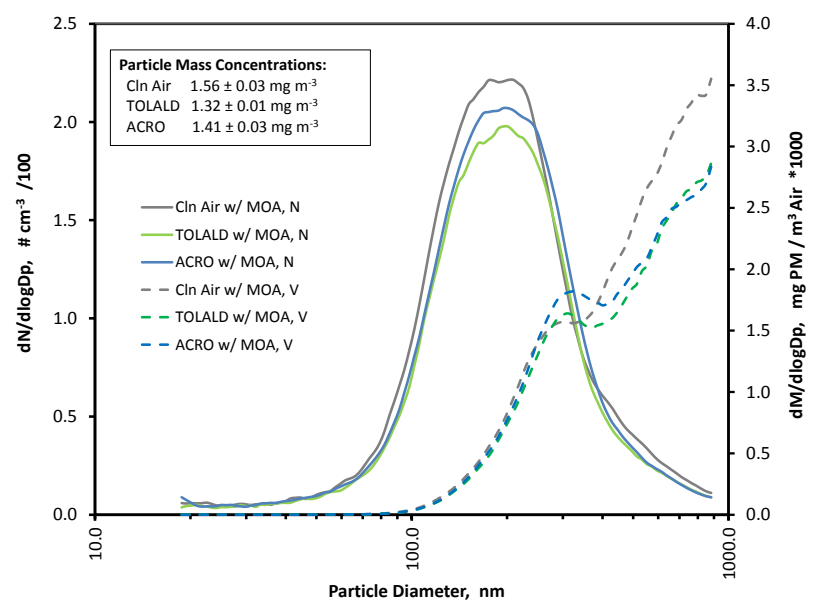

Fig. 2. MOA particle number and mass size distributions from the SMPS during Clean Air and single-VOC experiments. Particle mass concentrations reported in the inset were determined from TSP filter measurements.

(Fig. 2). Given that there was no super-micron mode observed with the Dusttrak in any of these experiments (data not shown) we make the assumption that the mass mode diameter is near $1 \mu \mathrm{m}$.

Chemical analysis of filter samples was only possible for the portion of the study that used ACRO. Filters taken from the chamber contained no detectable ACRO when (1) MOA was tested in clean air and, (2) when ACRO was tested without PM. Filter samples taken from the chamber when it contained ACRO mixed with MOA, however, yielded an average ACRO mass of $1.87 \mathrm{ng}$ per filter (corresponding to $1.06 \mathrm{ng}$ ACRO per mg PM). Further discussion of these results is given below.

\subsection{Toxicological response}

Figure 3 is the key for the colour coding and annotations used in Figs. 4-7.

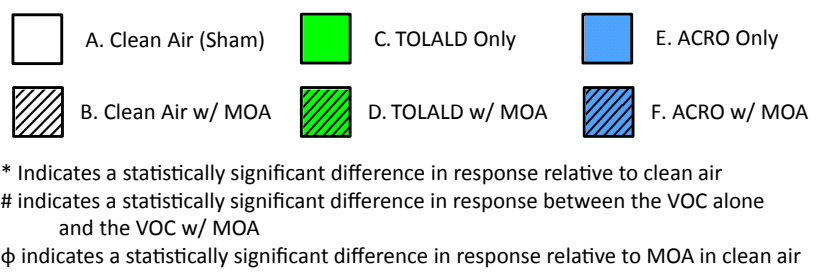

Fig. 3. Key for toxicology response plots. MOA is mineral oil aerosol, ACRO is acrolein, TOLALD is p-tolualdehyde.

The relative inflammatory responses to the mixtures that contained TOLALD are given in Fig. 4. The only significant increases in response from cells exposed by the gasonly method were observed when TOLALD was placed in the chamber without MOA (Exp. C; Fig. 4a). This exposure resulted in 3.2 and 2.7 times more IL-8 production than the clean air and clean air with MOA (Table 2). The only significant increase in response observed from cells exposed by the particle-only method was when TOLALD was mixed with MOA in the chamber (Exp. D; Fig. 4b, Table 2). The responses observed for cellular damage (LDH) resembled the inflammatory response, but with a greater magnitude in measured response (Fig. 5, Table 3).

Figures 6 and 7 show the relative response of lung cells to insult by the four air mixtures in which acrolein (ACRO) was used as the VOC of interest. As with TOLALD, when using the gas-only sampler, a significant response was only observed when ACRO was present in the chamber (Exps. E and F). Likewise, the only significant response from cells exposed with the particle-only sampler was observed when ACRO was mixed with MOA (Exp. F; Fig. 6b). A similar trend was observed with the measure of cellular damage (Fig. 7). Response ratios are summarized in Tables 4 and 5. Further discussion of results follows. 

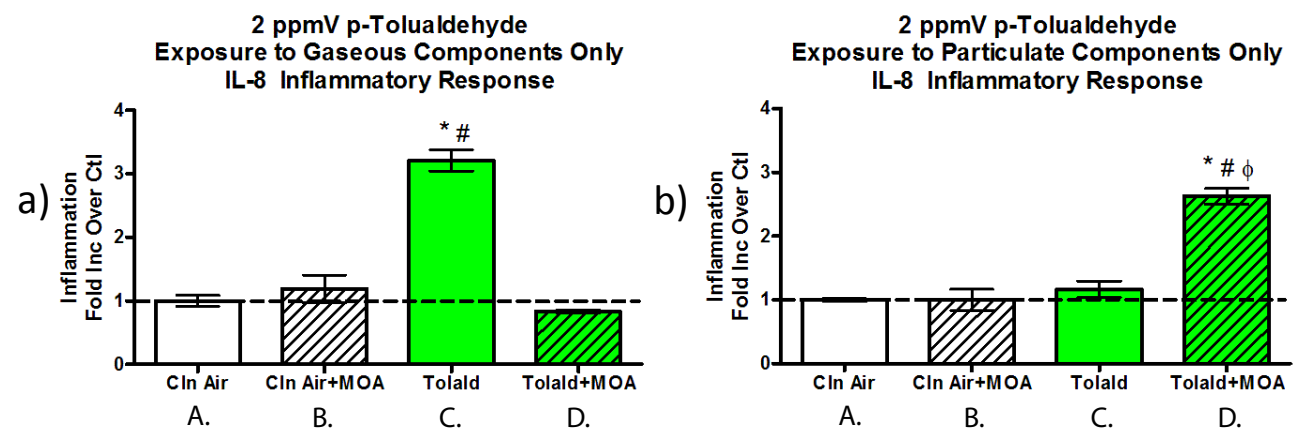

Fig. 4. The IL-8 inflammatory response of lung cells following exposure to four air mixtures. The response induced by exposure to (a) the gaseous components of each mixture and (b) the particle phase components of each mixture.
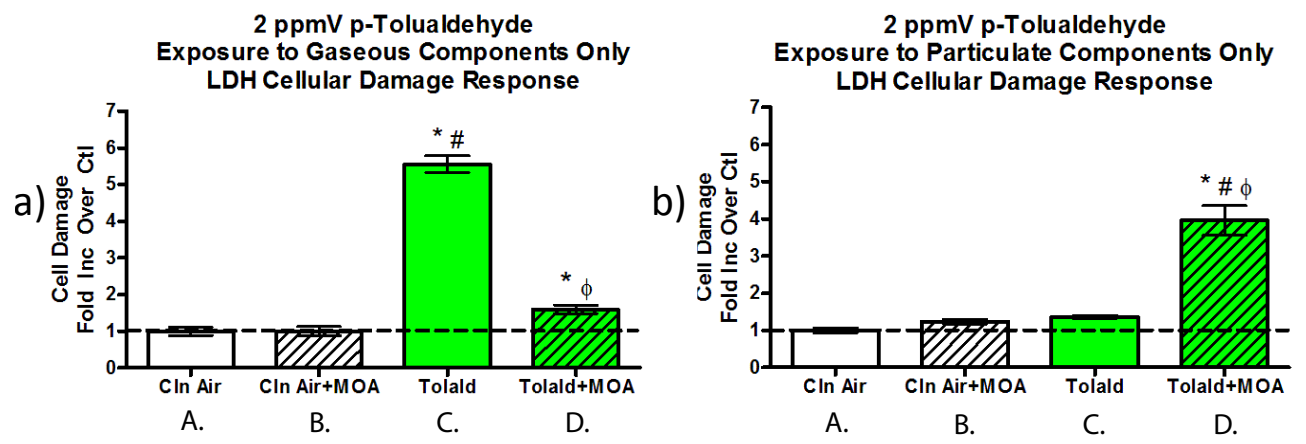

Fig. 5. Cellular damage following exposure to four air mixtures. The response induced by exposure to (a) the gaseous components of each mixture and (b) the particle-phase components of each mixture.

Table 2. Ratios of measured inflammatory responses (IL-8) for in vitro human lung cell exposures to TOLALD mixtures, (Table 1 and Fig. 4).

\begin{tabular}{|c|c|c|c|c|}
\hline \multicolumn{5}{|c|}{ Gas-Only Exposure } \\
\hline Reference Condition* & A. & B. & C. & D. \\
\hline A. Clean Air & 1.00 & 1.19 & 3.21 & 0.83 \\
\hline B. Clean Air & & 1.00 & 2.70 & 0.70 \\
\hline C. Clean Air TOLALD & & & 1.00 & 0.26 \\
\hline D. Clean Air TOLALD w/MOA & & & & 1.00 \\
\hline
\end{tabular}

PM-Only Exposure

\begin{tabular}{|c|c|c|c|c|}
\hline Reference Condition* & A. & B. & $\mathrm{C}$. & D. \\
\hline A. Clean Air & 1.00 & 1.00 & 1.17 & 2.63 \\
\hline B. Clean Air & & 1.00 & 1.17 & 2.63 \\
\hline C. Clean Air TOLALD & & & 1.00 & 2.25 \\
\hline D. Clean Air TOLALD w/MOA & & & & 1.00 \\
\hline
\end{tabular}

* MOA is mineral oil aerosol, TOLALD is p-tolualdehyde.
Table 3. Ratios of measured cellular damage (LDH) for in vitro human lung cell exposures to TOLALD mixtures, (Table 1 and Fig. 5).

\begin{tabular}{|c|c|c|c|c|}
\hline \multicolumn{5}{|c|}{ Gas-Only Exposure } \\
\hline Reference Condition* & A. & B. & C. & D. \\
\hline A. Clean Air & 1.00 & 1.00 & 5.55 & 1.59 \\
\hline B. Clean Air & & 1.00 & 5.53 & 1.59 \\
\hline C. Clean Air TOLALD & & & 1.00 & 0.29 \\
\hline D. Clean Air TOLALD w/MOA & & & & 1.00 \\
\hline \multicolumn{5}{|c|}{ PM-Only Exposure } \\
\hline Reference Condition* & A. & B. & C. & D. \\
\hline A. Clean Air & 1.00 & 1.24 & 1.37 & 3.96 \\
\hline B. Clean Air & & 1.00 & 1.11 & 3.20 \\
\hline C. Clean Air TOLALD & & & 1.00 & 2.90 \\
\hline D. Clean Air TOLALD w/MOA & & & & 1.00 \\
\hline
\end{tabular}


Table 4. Ratios of measured inflammatory responses (IL-8) for in vitro human lung cell exposures to ACRO mixtures, (Table 1 and Fig. 6).

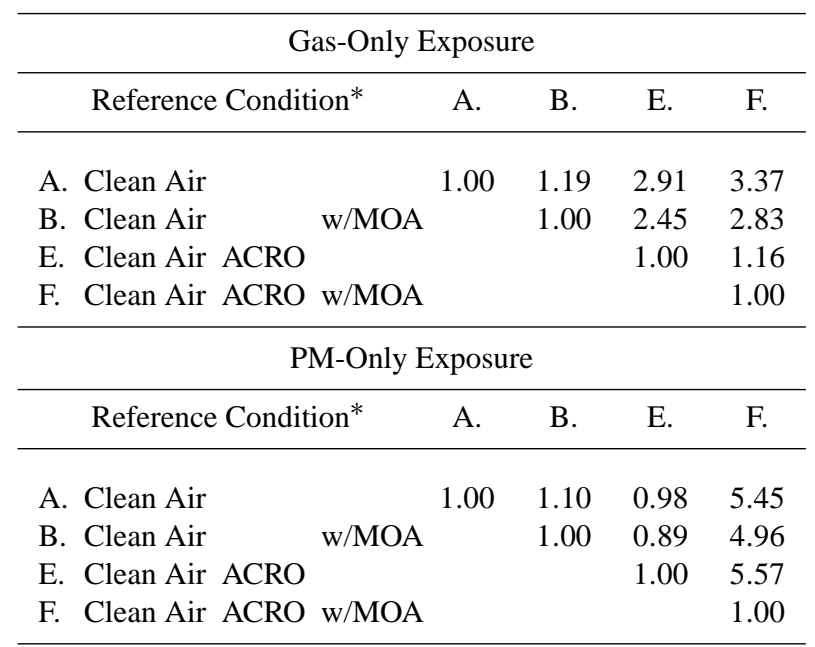

* MOA is mineral oil aerosol, ACRO is acrolein.

\section{Discussion}

This demonstration study is an effort to create a simplified and abstract model of processes that might occur in the ambient environment and human body. While simple, it provides us with results that would be difficult to detect directly in the ambient environment with human subjects. The latter conditions are subject to competing processes that, without insight, would likely mask the true causes of observed effects in these complex and open systems. The findings here permit us to apply the same causal reasoning resulting from this study to complex, photochemical systems with urban VOC mixtures and systems with real diesel PM; these additional findings are described in our two subsequent studies (Ebersviller et al., 2012a,b).

\subsection{Does PM “effect modification" occur?}

Here we discuss the argument to demonstrate and defend the existence of PM "effect modification" as called for by the NRC (NAS, 2004).

First, we have established that MOA itself is not toxic to the cells in either the gas-only or the PM-only exposure systems.

Even at the relatively high particle concentration in the MOA exposure in clean air, neither of the in vitro exposure systems registered an increase in toxicity from the clean air exposure with MOA present, demonstrating that MOA itself is not inherently toxic for the endpoints we used (Exp. B; Figs. 4-7). This was true even though ca. $0.2 \mathrm{mg} \mathrm{m}^{-3}$ more MOA was present than the average of the exposures with MOA and VOCs (Table 1). This lack of inherent acute toxicity allows us to draw more concrete conclusions about the
Table 5. Ratios of measured cellular damage (LDH) for in vitro human lung cell exposures to ACRO mixtures, (Table 1 and Fig. 7).

\begin{tabular}{|c|c|c|c|c|c|}
\hline \multicolumn{6}{|c|}{ Gas-Only Exposure } \\
\hline & Reference Condition* & A. & B. & E. & F. \\
\hline A. & Clean Air & 1.00 & 1.00 & 3.33 & 1.61 \\
\hline B. & Clean Air & & 1.00 & 3.31 & 1.60 \\
\hline E. & Clean Air ACRO & & & 1.00 & 0.48 \\
\hline & Clean Air ACRO w/MOA & & & & 1.00 \\
\hline \multicolumn{6}{|c|}{ PM-Only Exposure } \\
\hline & Reference Condition* & A. & B. & E. & F. \\
\hline A. & Clean Air & 1.00 & 1.22 & 1.08 & 2.20 \\
\hline B. & Clean Air & & 1.00 & 0.88 & 1.79 \\
\hline E. & Clean Air ACRO & & & 1.00 & 2.04 \\
\hline F. & Clean Air ACRO w/MOA & & & & 1.00 \\
\hline
\end{tabular}

* MOA is mineral oil aerosol, ACRO is acrolein.

source of observed cellular responses to particle-phase exposures by removing the chance of false-positive responses due to any inherent toxicity of the particle phase. Moreover, the particle size distribution of each exposure atmosphere was continually monitored (Fig. 2), so we are able to rule out the effects of particle size variation on toxicity.

Second, only gas-to-particle and particle-to-gas (i.e., phys$\mathrm{ical} /$ thermodynamic) processes were likely to happen during these dark experiments.

The experiments were carried out at night to prevent the particles themselves from having their toxicity altered by direct reaction with sunlight. In addition, any effect that variations in RH might have had on the cells was minimal, as the lowest RH encountered in the study was observed during the Clean Air with MOA exposure (Exp. B). No response was observed from the cells in this exposure, so the likelihood of RH causing the increase in response observed from the VOC-containing exposures is negligible. Thus it is highly likely that any increase in the toxicity of the particle phase was solely due to the dynamic uptake of gas-phase toxics. This is a significant distinction to make, since the interplay between gases and particles occurs constantly in the ambient environment.

Third, there is clear evidence that the EAVES sampler performed as it has in previous studies (de Bruijne et al., 2008, 2009a,b) and does not show significant response to gas-phase irritants or toxicants except in the presence of PM, and then only with the deposition field turned on.

TOLALD without MOA exhibited significant gas-phase responses for both irritation and cellular toxicity (Exp. C; Figs. $4 \mathrm{a}$ and 5a). In the PM-only exposure system, the exposure with TOLALD as a gas only (i.e., no PM) did not exhibit a significant response from either biological effect endpoint (Exp. C; Figs. 4b and 5b), again demonstrating that cells in 

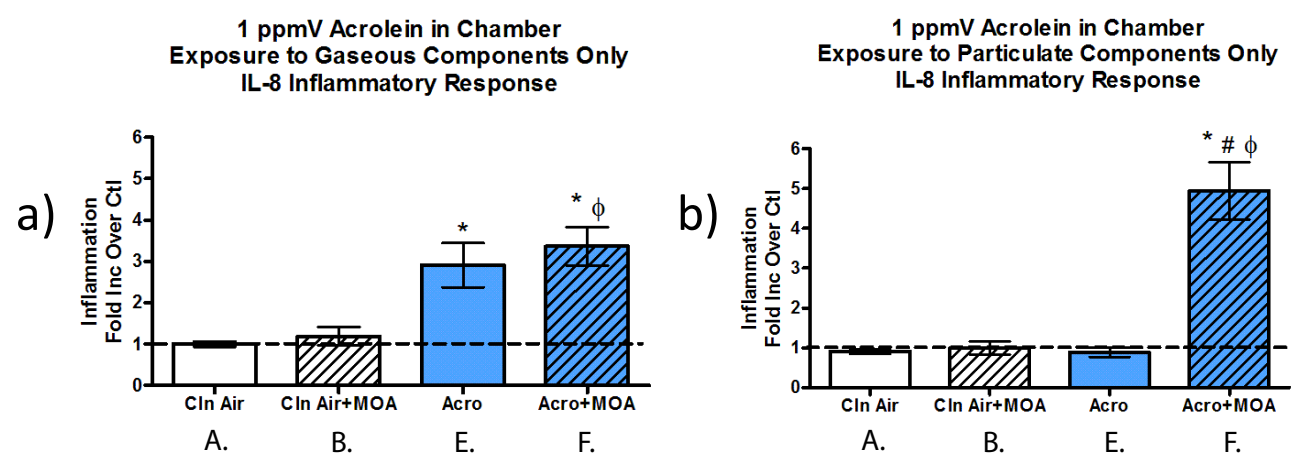

Fig. 6. The IL-8 inflammatory response of lung cells following exposure to four air mixtures. The response induced by exposure to (a) the gaseous components of each mixture and (b) the particle phase components of each mixture.
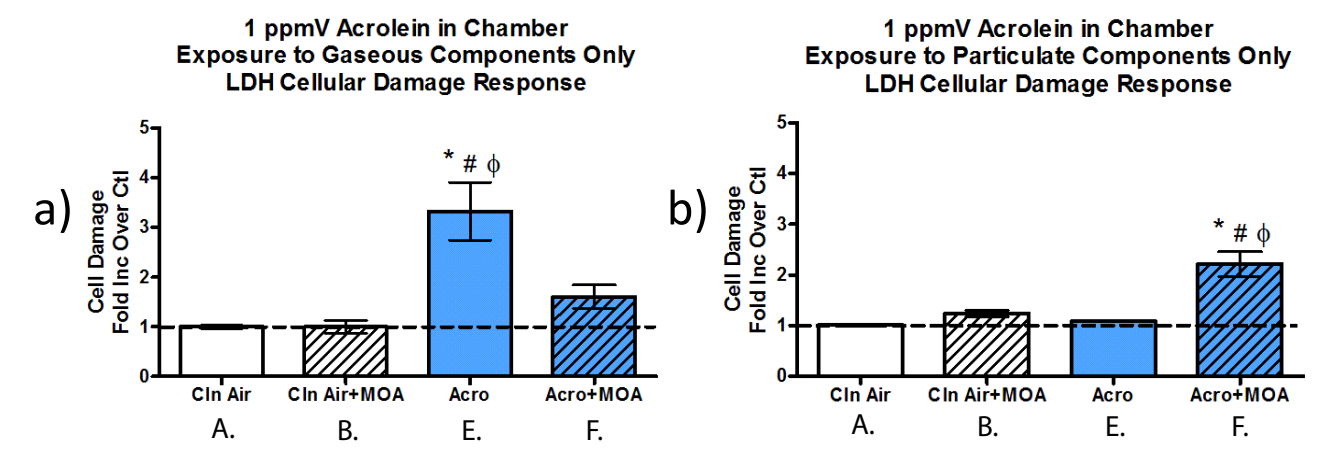

Fig. 7. Cellular damage following exposure to four air mixtures. The response induced by exposure to (a) the gaseous components of each mixture and (b) the particle-phase components of each mixture.

this exposure system are not responsive to gas-phase toxicants under these exposure conditions.

ACRO without MOA, even at one-half the concentration of TOLALD, exhibited significant gas-phase response for both irritation and cellular toxicity (Exp. E; Figs. 6a and 7a). In the PM-only exposure system, the exposure with ACRO as a gas only (i.e., no PM) showed no response (Exp. E; Figs. 6b and $7 \mathrm{~b}$ ), again showing that cells in this exposure system are not responsive to gas-phase toxicants under these exposure conditions.

Fourth, there is clear evidence for the transfer of gas-phase toxicity to the particle phase for both the semi-volatile TOLALD and the more-volatile ACRO gases.

The extent of this transfer is related to the volatility properties of the two test gases. The magnitude of the effects upon delivery can also differ because the two gases have different inherent toxicities and irritant properties. Furthermore, the two biological endpoints have a relationship: expression of IL-8 depends upon living cells, whereas, large-scale release of LDH occurs when cells die. While both markers can increase initially, usually IL-8 expression declines when LDH rises because the number of living cells needed to express the cytokine has decreased. This must be remembered when comparing relative changes in the markers across two different toxicants.

Also (to reiterate our discussion from the Introduction), the absorbed dose of a VOC from the air is determined by both its lipophilicity and its ability to diffuse through water (McClellan and Henderson, 1995; Schwarzenbach et al., 2003; Salem and Katz, 2006). If airway cells are to absorb VOCs, the VOCs must be transported to the air-liquid interface in the lung, where diffusion processes limit transfer of the VOCs to the liquid layer. Compounds with high aqueous solubility will usually be taken out of the airway early. Conversely, compounds with low aqueous solubility may have very low absorption by the airway, and the bulk of the inhaled gas will be exhaled immediately. Dissolution into PM will not only deliver both of these classes of compounds to a region of the lung they would not normally enter, it will also hold them at an elevated concentration for an extended period of time, thereby increasing their overall dose to that region of the lung (and possibly to the body as a whole).

PM is able to bypass the diffusion-limited transfer of species across the aqueous layer above the surface of the cells in the airway. Bypassing this transfer brings partitioned VOCs into direct contact with the cellular membrane, thereby altering the dosimetry of the VOCs. When species 
are delivered to the cell surface in this manner, simple diffusion will push the VOCs from the particle into the cellular membrane, where they can reside until they are able to diffuse into the cell body (Becker et al., 2003; Schwarzenbach et al., 2003). Once apolar and low-polarity organics become infused in the lipid layer of the cell membrane, they can resist cellular clearance processes. When VOCs enter the cell in this manner, they will most likely be free of endosomal membranes - giving them free access to all compartments of the cell, including the nucleus (McClellan and Henderson, 1995; Becker et al., 2003). If the VOCs are metabolised by cellular processes or diffuse across the capillary membrane into the bloodstream, it will simply shift the partitioning equilibrium to cause more of the toxicant to diffuse into the cell's interior, thereby maintaining an elevated dose (Foster and Costa, 2005).

What all of this means for our exposures is that the inherent differences in cell-toxicant contact time in our exposure systems are analogous to gaseous and particle-borne toxicant exposures in vivo. Therefore, the behaviour of the biological systems here is illustrative of the way that exposures in vivo may be modified by altering the method of delivery for these toxicants (PM-borne rather than gas-phase exposure).

Because TOLALD is less volatile than ACRO, the TOLALD with MOA system showed two interesting signals (Exps. C and D; Figs. 4 and 5).

Focusing initially on just the gas-phase exposure system, comparing TOLALD without MOA (Exp. C) to TOLALD with MOA (Exp. D), it is clear that there was a large decrease in the response with MOA present for both biological endpoints. For IL-8, the response changed from a 3.2-fold increase without MOA to only 0.8 -fold with MOA present. For $\mathrm{LDH}$ the response decreased from 5.5-fold without PM to only 1.6-fold with MOA present. This indicates a very substantial decrease in gaseous TOLALD in the presence of PM. Focusing on just the PM-only exposure results, comparing TOLALD without MOA (Exp. C) to TOLALD with MOA (Exp. D) it is clear that the PM has acquired a three-to-fourfold increase in its degree of irritancy and toxicity. Thus, for TOLALD with MOA, cellular toxicity has moved almost entirely from the gas-phase to the particle-phase.

Comparing ACRO without MOA (Exp. E) to ACRO with MOA (Exp. F), however, it is likely that more ACRO remained in the gas phase in the presence of the MOA than was observed for TOLALD (which is consistent with ACRO's higher volatility). In fact, there is no statistical difference in the IL-8 responses between Exp. E and Exp. F, which one might assume implies that the same amount of ACRO was present in the gas phase in both exposures. But comparing the LDH results between the Exp. E and Exp. F cases suggests another conclusion: that ACRO is a strong gaseous toxicant compound and causes a larger cell death (in Exp. E) actually suppressed the formation of IL-8 in Exp. E relative to Exp. F. When MOA was added and ACRO was taken up by the PM, the amount of cell death in the gas exposure de- creased (Fig. 7a), but the IL-8 expression for the gas exposure remained about the same (Fig. 6a). While this appears contradictory, the factors causing similar production of IL-8 in Exp. E and Exp. F might actually be different. There are at least two interpretations: (1) in Exp. F there was less ACRO in gas-phase, resulting in fewer cells actually dying. There may have been less expressed irritation on a per-living-cell basis, but it just happened to be equal to the amount observed in Exp. E because more cells survived to produce IL-8; (2) there was less ACRO in the gas-phase of Exp. F, which happened to produce the same amount of IL- 8 as the higher dose, but not as much cellular damage (and death), resulting in the lower observed release of LDH in Exp. F. One could conclude that Exp. F for LDH indicates that less gaseous ACRO was available than during Exp. E. This is supported by the PM-only exposure results. As shown in PM-only exposure results, for Exp. F (ACRO with MOA) the PM uptake of ACRO resulted in a 5.4-fold increase in irritation, as well as a significant 2.2-fold increase in cellular death. If we had measured absolute LDH (the LDH release from a membrane with $100 \%$ cell lysis induced), we might have been able to correct the IL- 8 yield and have a more definitive conclusion about the ACRO and PM. Despite this missing piece of evidence, there is little doubt that even volatile ACRO was taken up by the PM, and certainly changed the PM toxicity significantly.

We conclude that, from a purely experimental and operational point of view, the case for toxic gases being taken up by non-toxic PM and causing biological effects on cultured human lung cells has been demonstrated by the strong biological responses when formerly non-toxic PM is converted into toxic PM in the presence of toxic gases.

While this demonstration was in a simple system with limited processes, it did use representative semi-volatile and volatile toxic gases that are common to urban atmospheres and the model particle does have many of the properties of urban PM. Thus, these experimental findings can reasonably be extended to conclude that such processes as occurred in these tests' conditions $d o$ occur in the urban atmospheric environment. Subsequent studies (Ebersviller et al., 2012a,b) using photochemical transformations in urban VOC and diesel exhaust systems support this interpretation.

\subsection{How well do we understand the mechanisms?}

The experimental design included chemical measurements to aid in assessing VOC uptake on non-toxic PM. Filters were taken to quantify the PM mass injected and were also used for extractive carbonyl analysis. While not ideal due to potential loss of volatile and semi-volatile components during air passage over the filtered material, this is a commonly employed technique.

Unfortunately, further discussion of the particle uptake of TOLALD is hampered by the loss of the filter samples taken for chemical analysis due to a freezer failure. 
Table 6. Theoretical and observed values for partitioning of TOLALD and ACRO to PM.

\begin{tabular}{|c|c|c|c|}
\hline VOC & $\begin{array}{l}\text { The } \\
\text { Conc } \\
K_{\mathrm{p}}{ }^{\mathrm{a}}\end{array}$ & $\begin{array}{c}\text { etical } \\
\text { tration } \\
K_{\mathrm{Oa}}{ }^{\mathrm{b}} \\
\mathrm{VOC}\end{array}$ & $\begin{array}{c}\text { Observed } \\
\text { Concentration }\end{array}$ \\
\hline TOLALD & 1.87 & 2.77 & $\operatorname{missing} \mathrm{c}$ \\
\hline ACRO & 0.37 & 0.50 & $0.93 \pm 0.59$ \\
\hline
\end{tabular}

We can attempt to compensate for the loss of the TOLALD filter samples by calculating an estimate of the TOLALD loading of the MOA using partitioning theory $K_{\mathrm{p}}$ equations from Pankow (1997) and $K_{\text {oa }}$ equations from Schwarzenbach (2003). The results of these calculations are shown in Table 6. The theoretical calculated amount of TOLALD taken up by the MOA would be on the order of 1.87-2.77 ng TOLALD per mg MOA. This means that, according to partitioning theory, approximately $97 \%$ of the TOLALD mass remains in the gas-phase.

The experimental gas-phase biological effects for TOLALD without MOA and with MOA (Exp. D/Exp. C) show a ratio of 0.26 (IL-8) and 0.29 (LDH). It seems unlikely that such a large difference in biological effects would result from removing just $3 \%$ of the TOLALD from the gas phase. Of course, the use of relatively simple partioning theory may be misleading.

ACRO is (according to partitioning theory) even less likely to be found in the particle phase than TOLALD. Table 6 shows the same application of simple partitioning theory to ACRO, with predicted theoretical values from $0.37-0.50 \mathrm{ng}$ ACRO per mg PM. The analysis of filter samples taken from the air mixtures of ACRO and MOA, however, showed that measured uptake of ACRO was $0.93 \pm 0.59 \mathrm{ng}$ ACRO per $\mathrm{mg}$ $\mathrm{PM}$, which is ca. 1.8-2.5 times greater than predicted by theory.

While there is always the concern that a higher-thanexpected concentration of an analyte might be from contamination, the filter samples were handled in such a way as to completely segregate them from the possibility of absorbing ACRO from the laboratory air. ACRO has, to our knowledge, never entered the laboratory in which all filter handling and processing was performed (other than was brought in on these filter samples).

Further, while the gas-phase biological exposure results support that more ACRO may have remained in the gasphase after adding MOA than occurred in the TOLALD case, the uptake of ACRO by MOA is clearly shown by the particle-phase biological exposure results (that show a strong 5.5-fold increase in effect for IL-8 and a 2.2-fold increase for
LDH). Similar to the TOLALD case, it also appears that the gas-phase responses of ACRO did decrease in the presence of MOA, signifying at least partial loss of ACRO from the gas-phase (indicated by the loss of LDH signal).

One explanation for the higher-than-predicted concentration of ACRO in the particle phase may be the recent findings that realistic levels of humidity can facilitate particle uptake for water soluble compounds (Parikh et al., 2011; Lim et al., 2010). Other recent studies have also reported detecting species with higher-than-expected volatilities in ambient PM, where they can undergo polymerization processes (Liggio and McLaren, 2003; Hu and Kamens, 2007; Cao and Jang, 2008; Zhou et al., 2011). ACRO, while not included in the study by Liggio and McLaren, has a volatility that falls within the range of those tested. Furthermore, ACRO is known to polymerize readily, especially in an acidic environment. Polyacrolein itself has been associated with negative human health outcomes, such as Alzheimer's disease (Seidler and Yeargans, 2004; Liu et al., 2005; Seidler et al., 2006). Moreover, the acute inflammatory response observed indicates that, whatever form ACRO may be taking in the condensed phase, it is still capable of eliciting a biological effect.

If we assume that the observed biological responses are an indication that particles are more capable of picking up volatile species than expected (for both TOLALD and ACRO), it does not necessarily indicate that current partitioning theory is invalid. For instance, if small molecules are easier to dissolve in the condensed phase than currently believed, the calculation of activity coefficients may simply need to be adjusted, or a term may need to be added to account for the influence of humidity effects. For example, new research published by Carslaw et al. (2012), reported having to apply a scaling factor of 120 to make partitioning theory agree with experimental observations. In whatever way the theoretical calculations may need to be modified, it is clear that current partitioning theory is incapable of explaining these results.

It was not the goal of this work to develop or evaluate the theory of gas-particle partitioning (or whatever process may be responsible for the observed uptake), but rather to provide experimental evidence about the importance of these processes for advancing understanding of PM health-effects. It seems clear that further (and more focused) work is needed to understnad fully the mechanisms by which non-toxic PM acquires toxicity in both these simple test systems and in the urban atmosphere. Policy makers and research toxicologists may not wish to wait for this to be fully resolved, however, before adjusting their approaches to dealing with PM. 


\section{Conclusions}

These results may have important ramifications across the air pollution/health effects fields. This study has shown that atmospheric gases that are toxic can, through only physi$\mathrm{cal} /$ thermal processes, cause non-toxic PM to become toxic. Due to deposition and clearance mechanisms in the human body, the "newly toxic" PM can act as a pre-concentrator and delivery mechanism to deliver a dose of atmospheric gases to a region of the lung that might not normally encounter them. As discussed in the introduction, atmospheric gases delivered to the lung in this way may have an increased biological effect relative to that of the gas-phase toxic species. This may help explain the inability of laboratory-based toxicologists to replicate effects seen in near-roadway epidemiology studies that has confounded the risk assessment field and policy makers alike (Dreher, 2000; Schlesinger et al., 2006). The time scale for these inter-phase dynamics is on the order of seconds. What this means in the real world is that vehicle emissions (and other PM) may not be exceptionally toxic as they enter the atmosphere but, when mixed into an aged or ageing air mass, can change dramatically in composition and biological effect by the time they drift off-road and reach the general population. Thus, an important factor to consider is the role of PM as a carrier of gas-phase toxics into regions of the lungs they may not normally reach, where the toxic load can be released even if the PM mass is mostly expelled.

While the creation of oxidized daughter products has long been investigated for its potential to produce ozone and PM, toxicological work has remained largely focused on single pollutants or primary sources of PM (e.g., Weldy et al., 2011; Tsukue et al., 2010). This work demonstrates that the dynamic shifting of toxicity from the gas phase to the PM present in the mixture is likely to be an important component to understanding the response of individuals exposed in the ambient environment. This dynamic shift is an example of what the NRC was referring to when asking for evidence of "effect modification" (NAS, 2004). Further, it identifies an important (and currently neglected) source of PM toxicity, the reactive atmosphere itself. To incorporate the reactive atmosphere into toxicological studies fully, researchers must have a mechanism by which to photochemically age species in situ. Currently, very few biological exposure facilities have these kind of transformative capabilities available to them, resulting in exposure studies that miss the full complexity of the entanglements encountered in the ambient environment. What this means for their exposure studies is that they not only miss the full complexity of these entanglements, they likely miss important biological effects associated with PM that has been fully exposed to, and processed by, the atmosphere. It is these dynamic entanglements that we have shown here to be so important for cellular effects. Further demonstrations of these "effect modifications", in more complex and realistic atmospheric systems, are pro- vided in Part 2 and Part 3 of our studies (Ebersviller et al., 2012a,b).

\section{Supplementary material related to this article is available online at: http://www.atmos-chem-phys.net/12/ 12277/2012/acp-12-12277-2012-supplement.pdf.}

Acknowledgements. This research was supported in part by a grant from the National Institute of Environmental Health Sciences (P30ES010126) and in part by support from the Gillings School of Global Public Health's Gillings Innovation Laboratory Program for Research and Innovation Solutions. Publication costs were provided by the Department of Environmental Sciences and Engineering in the Gillings School of Global Public Health at the University of North Carolina at Chapel Hill.

Edited by: H. Saathoff

\section{References}

American Type Culture Collection (ATCC): Cell Biology, Designation: A549, http://www.atcc.org, 2011.

Becker, W., Kleinsmith, L., Hardin, J., and Raasch, J.: The World of the Cell, Benjamin Cummings, San Francisco, CA, 5th edn., 2003.

Cao, G. and Jang, M.: Secondary organic aerosol formation from toluene photooxidation under various $\mathrm{NO}_{\mathrm{x}}$ conditions and particle acidity, Atmos. Chem. Phys. Discuss., 8, 14467-14495, doi:10.5194/acpd-8-14467-2008, 2008.

Clayton, G. and Clayton F. (Eds.): Patty's Industrial Hygiene and Toxicology, Vol.2A, John Wiley Sons, New York, NY, 3th edn., 1982.

Carslaw, N., Mota, T., Jenkin, M., Barley, M. H., and McFiggans, G.: A significant role for nitrate and peroxide groups on indoor secondary organic aerosol, Environ. Sci. Technol., 46, 92909298, 2012.

de Bruijne, K., Ebersviller, S., Sexton, K. G., Jeffries, H. J., and Jaspers, I.: Comparing the Toxicity of Fresh and Aged Diesel Exhaust using Separate Particle and Gaseous Exposure Systems, The Toxicologist: Supplement to Toxicological Sciences, 102(1), 224.680, 2008.

de Bruijne, K., Ebersviller, S., Sexton, K. G., Jeffries, H. J., and Jaspers, I.: Comparing the Toxicity of Fresh and Aged Biodiesel and Diesel Exhaust using Separate Particle and Gaseous Exposure Systems, The Toxicologist: Supplement to Toxicological Sciences, 108, 42.689, 2009a.

de Bruijne, K., Ebersviller, S., Sexton, K. G., Lake, S., Leith, D., Goodman, R., Jetter, J., Walters, G., Doyle-Eisele, M., Woodside, R., Jeffries, H. J., and Jaspers, I.: Design and Testing of Electrostatic Aerosol In Vitro Exposure System (EAVES): An Alternative Exposure System for Particles, Inhal. Toxicol., 21, 91-101, 2009b.

Donahue, N., Robinson, A., Stanier, C., and Pandis, S.: Coupled Partitioning, Dilution, and Chemical Aging of Semivolatile Organics, Environ. Sci. Technol., 40, 2635-2643, 2006. 
Doyle, M., Sexton, K. G., Jeffries, H. E., Bridge, K., and Jaspers, I.: Effects of 1,3-Butadiene, Isoprene, and Their Photochemical Degradation Products on Human Lung Cells, Environ. Health Perspect., 112, 1488-1495, 2004.

Doyle, M., Sexton, K., Jeffries, H., and Jaspers, I.: Atmospheric photochemical transformations enhance 1,3-butadiene-induced inflammatory responses in human epithelial cells: The role of ozone and other photochemical degradation products, Chem. Biol. Interact., 166, 163-169, 2007.

Dreher, K.: Particulate matter physicochemistry and toxicology: in search of causality-a critical perspective, Inhal. Toxicol., 12, 4557, 2000.

Ebersviller, S., Lichtveld, K., Sexton, K. G., Zavala, J., Lin, Y.-H., Jaspers, I., and Jeffries, H. E.: Gaseous VOCs rapidly modify particulate matter and its biological effects - Part 2: Complex urban VOCs and model PM, Atmos. Chem. Phys., 12, 1229312312, doi:10.5194/acp-12-12293-2012, $2012 \mathrm{a}$.

Ebersviller, S., Lichtveld, K., Sexton, K., Zavala, J., Lin, Y.-H., Jaspers, I., and Jeffries, H.: Gaseous VOCs rapidly modify particulate matter and its biological effects - Part 3: Petroleum diesel and biodiesel oxidations, Atmos. Chem. Phys. Discuss., in preparation, 2012b.

EPA, U.: Air Toxics Index, http://www.epa.gov/ttn/atw/orig189. html, 2012.

Farina, F., Sancini, G., Mantecca, P., Gallinotti, D., Camatini, M., and Palestini, P.: The acute toxic effects of particulate matter in mouse lung are related to size and season of collection, Toxicol. Lett., 202, 209-217, 2011.

Foster, M. and Costa, D.: Air Pollutants and the Respiratory Tract, Taylor and Francis, New York, NY, 2nd edn., 2005.

Grosjean, D., Grosjean, E., and Gertler, A. W.: On-Road Emissions of Carbonyls from Light-Duty and Heavy-Duty Vehicles, Environ. Sci. Technol., 35, 45-53, 2001.

Healy, R. M., Wenger, J. C., Metzger, A., Duplissy, J., Kalberer, M., and Dommen, J.: Gas/particle partitioning of carbonyls in the photooxidation of isoprene and 1,3,5-trimethylbenzene, Atmos. Chem. Phys., 8, 3215-3230, doi:10.5194/acp-8-3215-2008, 2008.

Hinds, W.C.: Aerosol Technology: Properties, Behavior, and Measurement of Airborne Particles, John Wiley Sons, New York, NY, 2nd edn., 1999.

$\mathrm{Hu}, \mathrm{D}$. and Kamens, R.: Evaluation of the UNC toluene-SOA mechanism with respect to other chamber studies and key model parameters, Atmos. Environ., 41, 6465-6477, 2007.

Jaspers, I., Flescher, E., and Chen, L.: Ozone-induced IL-8 expression and transcription factor binding in respiratory epithelial cells, Am. J. Physiol. Lung. Cell Mol. Physiol., 272, 3 Pt 1, L504-511, 1997.

Jeffries, H., Fox, D., and Kamens, R.: Outdoor Smog Chamber Studies: Light Effects Relative to Indoor Chambers, Environ. Sci. Technol., 10, 1006-1011, 1976.

Jeffries, H., Sexton, K., Kamens, R., and Holleman, M.: Outdoor Smog Chamber Experiments: Reactivity of Methanol Exhaust, Environmental Protection Agency, Office of Mobile Sources, Ann Arbor, MI, 1985.

Kamens, R. and Jaoui, M.: Modeling Aerosol Formation from apinene $+\mathrm{NOx}$ in the Presence of Natural Sunlight Using Gas Phase Kinetics and Gas-particle Partitioning Theory, Environ. Sci. Technol., 35, 1394-1405, 2001.
Kamens, R., Jeffries, H., Gery, M., Wiener, R., Sexton, K., and Howe, G.: The Impact of a-pinene on Urban Smog Formation: An Outdoor Chamber Study, Atmos. Environ., 15, 969-981, 1981.

Lee, S., Jang, M., and Kamens, R.: SOA formation from the photooxidation of a-pinene in the presence of freshly emitted diesel soot exhaust, Atmos. Environ., 38, 2597-2605, 2004.

Li, T.-H., Hooper, K., Fischer, E., Laskin, D. L., Buckley, B., and Turpin, B. J.: An exposure system to study the effects of watersoluble gases on PM-induced toxicity, Inhal. Toxicol., 12, 563576, 2000.

Lichtveld, K., Ebersviller, S., Sexton, K. G., Vizuete, W., Jaspers, I., and Jeffries, H. J.: In Vitro Exposures in Diesel Exhaust Atmospheres: Resuspension of PM from Filters versus Direct Deposition of PM from Air, Environ. Sci. Technol., 46, 9062-9070, 2012.

Lieber, M., Smith, B., Szakal, A., Nelson-Rees, W., and Todaro, G.: A continuous tumor-cell line from a human lung carcinoma with properties of Type II alveolar epithelial cells, International Journal of Cancer, 17, 62-70, 1976.

Liggio, J. and McLaren, R.: An optimized method for the determination of volatile and semi-volatile aldehydes and ketones in ambient particulate matter, Int. J. Environ. Anal. Chem., 83, 819835, 2003.

Lim, Y. B., Tan, Y., Perri, M. J., Seitzinger, S. P., and Turpin, B. J.: Aqueous chemistry and its role in secondary organic aerosol (SOA) formation, Atmos. Chem. Phys., 10, 1052110539, doi:10.5194/acp-10-10521-2010, 2010.

Liu, X., Jeffries, H., and Sexton, K.: Hydroxyl radical and ozone initiated photochemical reaction of 1,3-butadiene, Atmos. Environ., 33, 3005-3022, 1999a.

Liu, X., Jeffries, H., and Sexton, K.: Atmospheric photochmical degradation of 1,4-unsaturated dicarbonyls, Environ. Sci. Technol., 33, 4212-4220, 1999b.

Liu, X., Lovell, M., and Lynn, B.: Development of a Method for Quantification of Acrolein-Deoxyguanosine Adducts in DNA Using Isotope Dilution-Capillary LC/MS/MS and Its Application to Human Brain Tissue, Anal. Chem., 77, 5982-5989, 2005.

May, K.: The Collison nebulizer: description, performance and application, Aerosol Sci., 4, 235-243, 1973.

McClellan, R. and Henderson, R.: Concepts in Inhalation Toxicology, Taylor and Francis, Washington, DC, 2nd edn., 1995.

NAS: National Research Council Research Priorities for Airborne Particulate Matter, vol. IV Continuing Research Progress, 98102, National Academies Press, Washington, DC, 2004.

Pankow, J., Liang, C., Odum, J., and Seinfeld, J.: Gas/Particle Partitioning of Semivolatile Organic Compounds to Model Inorganic, Organic, and Ambient Smog Aerosols, Environ. Sci. Technol., 31, 3086-3092, 1997.

Parikh, H., Carlton, A., Vizuete, W., Chen, E., and Kamens, R.: Modeling secondary organic aerosol using a dynamic partitioning approach incorporating particle aqueous-phase chemistry, Atmos. Environ., 45, 1126-1137, 2011.

Salem, H. and Katz, S.: Inhalation Toxicology, Taylor and Francis, New York, NY, 2nd edn., 2006.

Schlesinger, R., Kaunzli, N., Hidy, G., Gotschi, T., and Jerrett, M.: The health relevence of ambient particulate matter characteristics: coherence of toxicological and epidemiological inferences, Inhal. Toxicol., 18, 95-125, 2006. 
Schwarzenbach, R., Gschwend, P., and Imboden, D.: Environmental Organic Chemistry, Wiley-Interscience, Hoboken, NJ, 2nd edn., 2003.

Seagrave, J., Knall, C., McDonald, J., and Mauderly, J.: Diesel Particulate Material Binds and Concentrates a Proinflammatory Cytokine That Causes Neutrophil Migration, Inhal. Toxicol., 16, 93-98, 2004.

Seidler, N. and Yeargans, G.: Albumin-bound polyacrolein: implications for Alzheimers's disease, Biochemical and Biophysical Research Communications, 320, 213-217, 2004.

Seidler, N., Craig, H., and Squire, T.: Endogenous plastic composite material in the Alzheimer's brain, Med Hypotheses, 67, 467-470, 2006.

Sexton, K. G., Jeffries, H. J., Jang, M., Kamens, R. M., Doyle, M., Voicu, I., and Jaspers, I.: Photochemical products in urban mixtures enhance inflammatory responses in lung cells, Inhal. Toxicol., 16, 107-114, 2004.

Steenhof, M., Gosens, I., Strak, M., Godri, K. J., Hoek, G., Cassee, F. R., Mudway, I. S., Kelly, F. J., Harrison, R. M., Lebret, E., Brunekreef, B., Janssen, N. A., and Pieters, R. H.: In vitro toxicity of particulate matter (PM) collected at different sites in the Netherlands is associated with PM composition, size fraction and oxidative potential - the RAPTES project, Part Fibre Toxicol, 8, $1-15,2011$.

Termonia, M., Lacomblez, B., and Munari, F.: Optimization of Cold Split-Splitless Injector, Journal of High Resolution Chromatography \& Chromatography Communications, 11, 890-895, 1988.
Tsukue, N., Okumura, H., Ito, T., Sugiyama, G., and Nakajima, T.: Toxicological evaluation of diesel emissions on A549 cells, Toxicol In Vitro, 24, 363-369, 2010.

Weldy, C. S., Wilkerson, H. W., Larson, T. V., Stewart, J. A., and Kavanagh, T. J.: Diesel particulate exposed macrophages alter endothelial cell expression of eNOS, iNOS, MCP1, and glutathione synthesis genes, Toxicol In Vitro, 25, 2064-2073, 2011.

Yu, J., Jeffries, H. E., and Le Lacheur, R.: Identifying Airborne Carbonyl Compounds in Isoprene Atmospheric Photooxidation Products by Their PFBHA Oximes Using Gas Chromatography/Ion Trap Mass Spectrometry, Environ. Sci. Technol., 29, 1923-1932, 1995.

Yu, J., Jeffries, H., and Sexton, K. G.: Atmospheric photo oxidation of alkylbenzenes - I. Carbonyl product analyses, Atmos. Environ., 31, 2261-2280, 1997.

Zhou, Y., Zhang, H., Parikh, H., Chen, E., Rattanavaraha, W., Rosen, E., Wang, W., and Kamens, R. M.: Secondary organic aerosol formation from xylenes and mixtures of toluene and xylenes in an atmospheric urban hydrocarbon mixture: Water and particle seed effects, Atmos. Environ., 45, 3882-3890, 2011. 